\title{
Fight! Robot, Fight!
}

\author{
The Amateur Robotics Movement in the United States \\ John P. Sullins, Sonoma State University, United States of America
}

\begin{abstract}
The study of Robotics was once the exclusive realm of elite research universities and corporations. The costs and logistics of building, programming, and maintaining a robotics platform in past generations were too high for the hobbyist or independent researcher. Over the last decade this has radically changed. Amateur robotics clubs are thriving, and knowledge generated by the robotics and AI research projects of the past, is now converging with the home and amateur robotics movement through inexpensive robotics platforms such as the Lego ${ }^{\circledR}$ Mindstorms ${ }^{\mathrm{TM}}$. $k i t s$. In addition to this, robot fighting leagues have also become very popular wherein participant build ingenious machines of destruction, which they operate via telerobotics in mock gladiatorial combat. The convergence of high-tech expertise with the home and amateur user presents a fascinating case study of the successful introduction of AI technologies into our everyday lives. We will look at how home users and hobbyists are creatively reshaping AI technology and identify the social values that are impacting, and being impacted by, the development of the home robotics community. In this paper I will review some of the recent developments in the home robotics movement that point towards greater collaborative research in robotics across cultures and between professional and hobbyist.
\end{abstract}

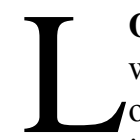

OCKED IN A cage with transparent Lexan walls, two combatants take their positions at opposite corners. The master of ceremonies introduces the contestants along with their builders then, with a shout of "fight robots, fight!" The machines begin to circle each other while hundreds of spectators cheer them on. Each of the robotic contestants weighs in at more than one hundred kilograms and the arena resounds as they batter the cage, and each other, in their efforts to destroy their antagonist. Finally, in a shower of sparks and acrid smoke one of the robots ceases to function, and the bout is over. The crowd cheers the surviving machine as it spins in victorious celebration. Off to the side of the arena, almost unnoticed, the human drivers and builders of the robot take a bow, while those of the losing machine haul their wreck back to the pits where dozens of other robot enthusiast prepare their machines for the rest of the days fights.

This scene plays itself out dozens of times nearly every weekend in regional, national and international robot fighting events. While many people are familiar with the professional, highly polished, television shows that showcase robot fighting such as Battle Bots $^{\circledR}$, or Robot Wars ${ }^{\circledR}$, few people know that there are hundreds of amateur organizations where people meet on the weekends to pursue their dreams of mechanical mayhem.

In addition to these activities, there is also a very large, and still growing, industry in educational robotics. Here the concentration is on building teams and understanding technology through the use of robots, which are built to compete in various ball sports or other technical challenges.

While much of the activity I will focus on in this paper is taking place in the United States, amateur robotics is a worldwide phenomenon and takes on distinct regional flavours. It is fascinating to compare and contrast, for instance, the amateur robotics enthusiast from Japan and Korea with their counterparts in the US so I will mention a few observations regarding that topic as well, all of which I witnessed at the 2004 Robolympics $^{1}$ in San Francisco California where there was a significant intermixing of robot fighters and educational robo-enthusiasts from both sides of the Pacific.

\footnotetext{
${ }^{1}$ This event is now called the Robogames (http://robogames.net/).
} 


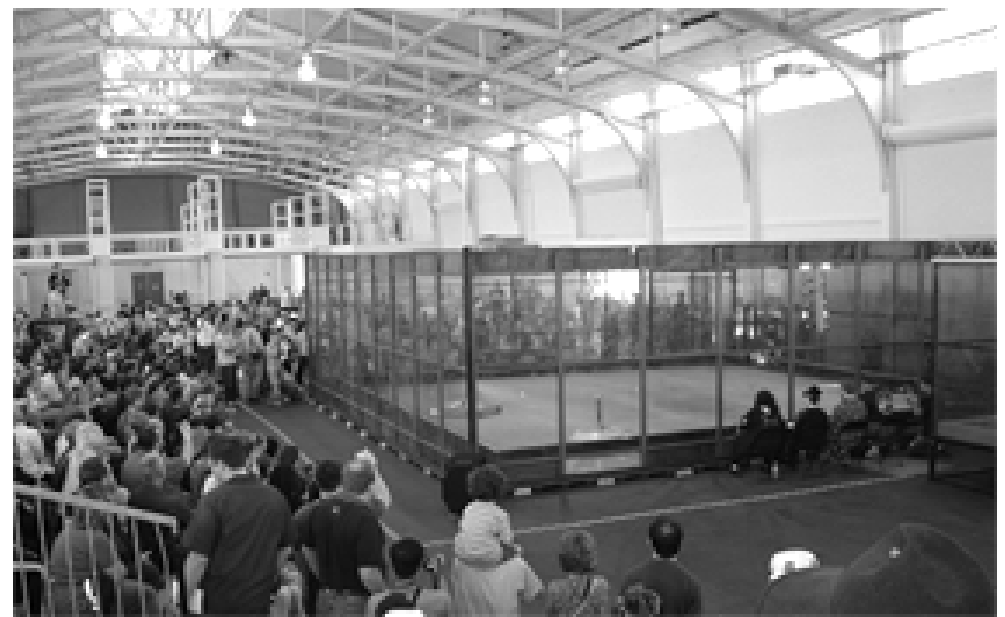

Figure 1: Fighting Robots battle in the Arena at the 2004 Robolympics in San Francisco California. Photo taken by the author.

\section{Important Events in American Amateur Robotics}

Robotics and automation has a long and interesting past beginning with the clockwork automata of the eighteenth century (Brooks 2002). Research in robotics, has up until now, largely been the province of big industry and academia. ${ }^{2}$ But, by the 1970 's amateur robotics began to take shape, emerging from the hobby electronics industry. In 1977 the Robotics Society of America was organized as a non-profit group of like-minded hobbyists who meet to trade ideas and inspiration. There are many organizations and clubs like the RSA but it is one of the largest. These groups have traditionally been interested in making autonomous mobile robots that do things like navigate through a maze, follow lines drawn on the ground, walk or crawl over uneven terrain, etc. These early garage experimenters were hampered by the cost of computer and electronic parts, but by the late eighties and early nineties this constraint was beginning to change. Today robotics enthusiasts have access to kits and components that only large wellfunded research institutions could have afforded in the past. This change has brought about a minor renaissance in home robotics that has greatly expanded the membership in hobby robotics groups. Today there are hundreds of these organizations that cater to all ages and all skill levels.

\section{Important innovations}

There are a number of important recent innovations that have encouraged the blossoming of the home robotics movement. Chief among them has been the development of the LEGO ${ }^{\circledR}$ Mindstorms ${ }^{\mathrm{TM}}$ kit. Released in 1998, this kit was the culmination of a fif- teen-year collaboration between the LEGO $^{\circledR}$ Group of Denmark and the MIT Media Lab (Brand 1987, Ferrari 2002). It grew out of Seymour Papert's work on the LOGO Turtle robotic toys that were developed in the late 70's at the Media lab as an educational tool (Papert 1980). Refining the ideas advanced in the LOGO Turtle project further, LEGO ${ }^{\circledR}$ Mindstorms $^{\mathrm{TM}}$ is a very powerful toy that couples the wonderfully engineered LEGO ${ }^{\circledR}$ bricks building systems with a brain brick or (RCX) that encases a Hitachi H8 microcontroller to which can be attached various sensors to give it information about its surroundings and motors to power one's robot for motility and other actions. In addition to these components, there are the ingenious software packages that are used to program the brick. Some of these programs are proprietary, such as the Mindstorms ${ }^{\text {TM }}$ or LEGO ${ }^{\circledR}$ LAB $^{\mathrm{TM}}$, programming environments, but others are freeware such as the more powerful NQC and Bircx Command Centre, which were developed by home robotics enthusiasts to enhance the capabilities of these machines.

While LEGO $^{\circledR}$ Mindstorms ${ }^{\mathrm{TM}}$ is the most popular, there are many other robotics kits available, ranging from the very inexpensive and basic, to those that are more expensive but with more power and versatility. Still, even the most expensive kits are less then a couple thousand dollars and give the home experimenter access to components and software that used to be very expensive indeed and in past decades would have been available only to large research institutions.

There are also a number of retail outlets such as Mondotronics, The Robot Marketplace, or Robotoys, which make it very easy for home users to acquire

\footnotetext{
${ }^{2}$ For a good review of academic and industrial research in autonomous robotics as of the turn of the century see Menzel and D'aluisio, Robosapiens, MIT Press 2000.
} 
all manner of robotic technology. ${ }^{3}$ In fact, the growing demand for robotics in consumer electronics is now being addressed by tradeshows specifically designed for robotics companies to showcase their mobile robotics products. Two of these events are called RoboNexus and RoboBusiness and are proving to be well attended. ${ }^{4}$ While this market is nowhere near as large as that of the personal computer, it is as large as that of traditional industrial robotics, and it is growing quickly. According to studies by the Japan Robotics Association, the United Nations Economic Commission, and the International Federation of Robotics, in 2005 the personal and service robotics market will be worth $\$ 5.4$ Billion, equal that of industrial robotics, and by 2025 is projected to be about $\$ 51.7$ billion or four times the size of the industrial robotics market, and this is excluding military and small toy robotics sales. ${ }^{5}$

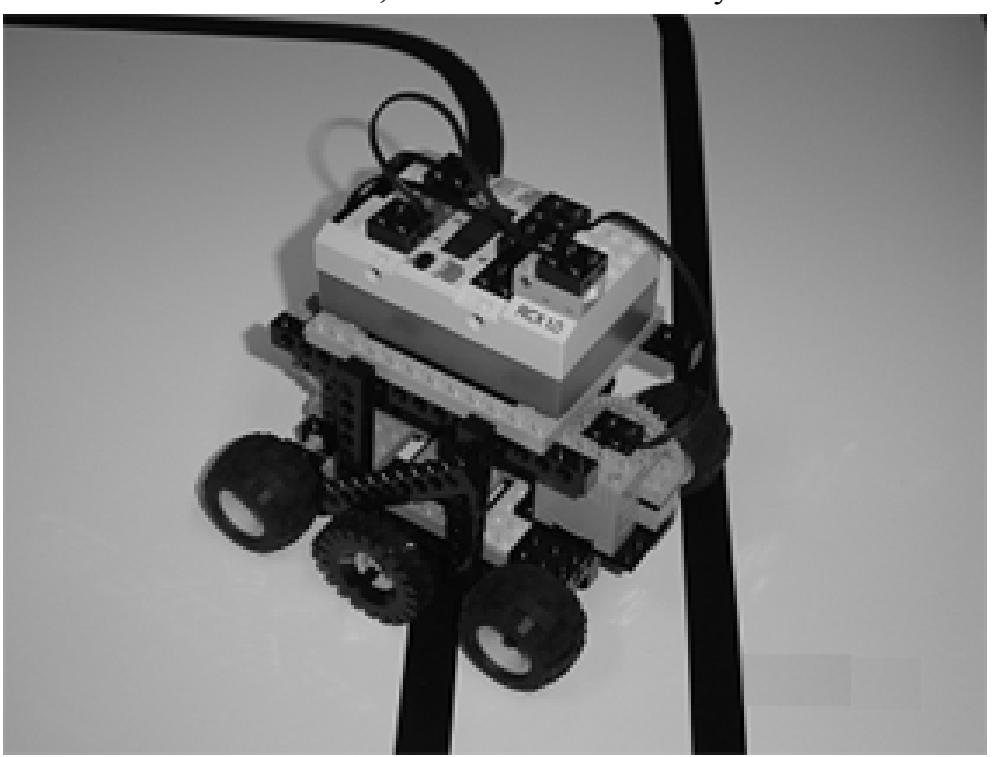

Figure 2: Example of a robot built with the LEGO ${ }^{\circledR}$ Mindstorms ${ }^{\mathrm{TM}}$ kit. Photo taken by the author.

The most thriving commercial robotics product to date has been the explosion of robotic vacuum cleaners starting in 2003. In the US, Asia, and Europe, a number of companies such as Hitachi and Kärcher have ventured into this market (Kahney 2003). In the US the most successful has been an upstart company called iRobot. ${ }^{6}$ Their robotic vacuum product, the Roomba ${ }^{\circledR}$, sells for under $\$ 200$ (US), and is sold in a number of big retail outlets. By July 2004 it had sold over 500,000 robots. One of the most interesting things about this machine is that home users have begun to hack them in order to make them smarter, or faster, or just more fun. ${ }^{7}$ The company iRobot, co-founded by the famous MIT mobile robot researcher, Rodney Brooks, has endorsed this activity and a growing cult following has begun to form around this robot as a platform for experimentation. ${ }^{8}$ As more and more products like this make it to the market place amateur robotics can only continue to flourish.

\section{The Dual Trajectory of American Amateur Robotics}

Even though home and hobby robotics is a relatively recent development, it is already too difficult to follow all of the various fads and trends taking place. Still, in American amateur robotics we can easily see two main trajectories developing one in robot fighting leagues and the other in education. Both of these trends are worth looking at from the standpoint of the philosophy of technology as they provide provocative case studies for exploring the social values that are shaping this emerging technology. From this we can not only learn a little about American society in the early twenty-first century, but also critique the design choices being made, hopefully this will contribute to better designs and more useful robotics technologies.

\footnotetext{
${ }^{3}$ Mondotronics (http://www.robotstore.com/), The Robot Marketplace (http://www.robotmarketplace.com/), Robotoys (http://www.robotoys.com/home.html)

${ }^{4}$ Robonexus is a consumer trade show (http://www.robonexus.com/index.html) and Robobusiness is for industry members (http://www.roboevent.com/).

${ }^{5}$ Data aquired here: (http://www.robonexus.com/roboticsmarket.htm)

${ }^{6} \mathrm{http}: / /$ www.irobot.com/home.cfm

${ }^{7}$ For example look at the Maggy Project (http://www.villela.com/roombarobot/)

${ }^{8} \mathrm{http}: / /$ www.roombacommunity.com/
} 


\section{Fighting}

Let us first turn to the popular sport of robot fighting. This sport combines the skills of hot rod gear-heads and techie computer geeks, with the violence of gladiatorial combat, and wraps it all up in the aesthetics of punk, hardcore, industrial, and metal music. Here we see the naked expression of the techno-lust, conspicuous consumption, and bellicosity that thrives in the industrial West.

This sport is perhaps best known in its incarnation as the television show; BattleBots ${ }^{\circledR}$, which first appeared in 1999. ${ }^{9}$ This television show has since been cancelled but others have taken its place, such as the UK's Robot Wars. ${ }^{10}$

I believe that this sport received some of its inspiration from the avant-garde artist collective known as Survival Research Laboratories (SRL), and other groups like them that have been experimenting for some time with the art of extreme robotics. ${ }^{11}$ Ever since 1979, SRL, headed by Mark Pauline, has been holding semi-clandestine events where machines of the artists' creation have pummelled each other into obliteration in front of large crowds who hear about the event through hearsay or via mailing lists only shortly before it happens. Billed as "the most dangerous shows on earth," SRL attempts to take their audience as close to experiencing combat as one can get and still have a reasonable chance of survival. Pauline has provocatively claimed, “...war is a spectator sport," and his events certainly appeal to that portion of our personality that revels in destruction and thrills at the sight of fire (Balthaus ed. 1988). Beyond the techno-erotic thrill of mechanical violence, these shows also ingeniously co-opt industrial, scientific, and military technology, and place them in situations their designers could have never imagined, yet for which they seem completely suited. There can be no doubt that there is a little Mark Pauline in every one of the people that partake in robot combat.

\section{The Social Role of Robot Fighting}

It would be too easy to dismiss the robot-fighting phenomenon as juvenile, or at best dysfunctional. Its relatively broad appeal cuts across many of the other social barriers in place in America. Although, reasonably affluent white men largely pursue the sport, it would be wrong to suggest that there are not important exceptions to this trend. Robot fighting is a part of American society and its enthusiasts reflect the diversity the American demographic. There is a growing amount of diversity amongst the participants as well as in the audience members. Also, women make up a large part of the participants and fans of this sport. Due to this wide appeal, it is not possible to discharge this activity entirely as an escapist fantasy. Even if that may be the motivation of some of its participants, I think there are more important values at work shaping this phenomenon.

I would like to argue that there are at least three social values worth looking at here: the robot as body transcendence, the home robot as a creative transformation of the commercially given, and the robot as civil mirror of military might.

\section{The Robot as Body Transcendence}

As in many other cultures, there is a strong urge amongst Americans to transcend the limits of their natural bodies. I have argued that this drive seems to stem from Judeo-Christian influence and that this drive is playing itself out with biotechnology and extreme body modification and other immersive technologies (Sullins 2001). The cognitive scientist Andy Clark has suggested that our brains have evolved a somewhat plastic notion of our embodiment and it can easily adapt to technological extensions and prosthetics (Clark 2003). Whatever the root of this value, one can easily see that it plays a role in robot fighting. The fighting robots themselves can do little on their own; they are actually tellerobots that are operated by human driver(s) via remote control. Thus, all their interesting behaviour is the direct result of their human operators who stand safely outside of the fighting arena. This reality is not focused on at the event. Except for the awards ceremony, the human operators do not share much of the spotlight with their robotic creations. In a sense they do not have to, since the robots are the preferred persona of their creators. Where we might be soft and unimpressive, our bots are hard bodied, fire breathing, saw blade wielding, killing machines. In robot fighting, what is praiseworthy is not who we are but what we create. While many of the builders and drivers of these robots have interesting personalities and histories of their own, it is the robots that we fetishize. If you watch Battlebots ${ }^{\circledR}$ you know the robot BioHazard, but may not know its builders.

Robots have bodies that are stronger and more capable then ours, and they have the ability to fight and die over and over just as the mythic warriors in Valhalla do. The violence done on them is thus not morally repugnant. At worst it represents a small financial loss to the vanquished team, but no real physical harm is done. In this way one can truly experience, even if just for the duration of a bout, near complete body transcendence - a dream we inherit from our culture.

\footnotetext{
${ }^{9}$ http://www.battlebots.com/

${ }^{10} \mathrm{http}: / /$ www.g4tv.com/robotwars/index.html

$11 \mathrm{http}: / /$ www.srl.org/
} 


\section{Creative Transformation of the Commercially Given}

A second value apparent in robot fighting is the ability of the robot builders to transform commer- cially given products into amazing new creations. Robot fighting is still a place where the creative and technical skills of the roboticist can shine through. It is easy to critique our technological society by

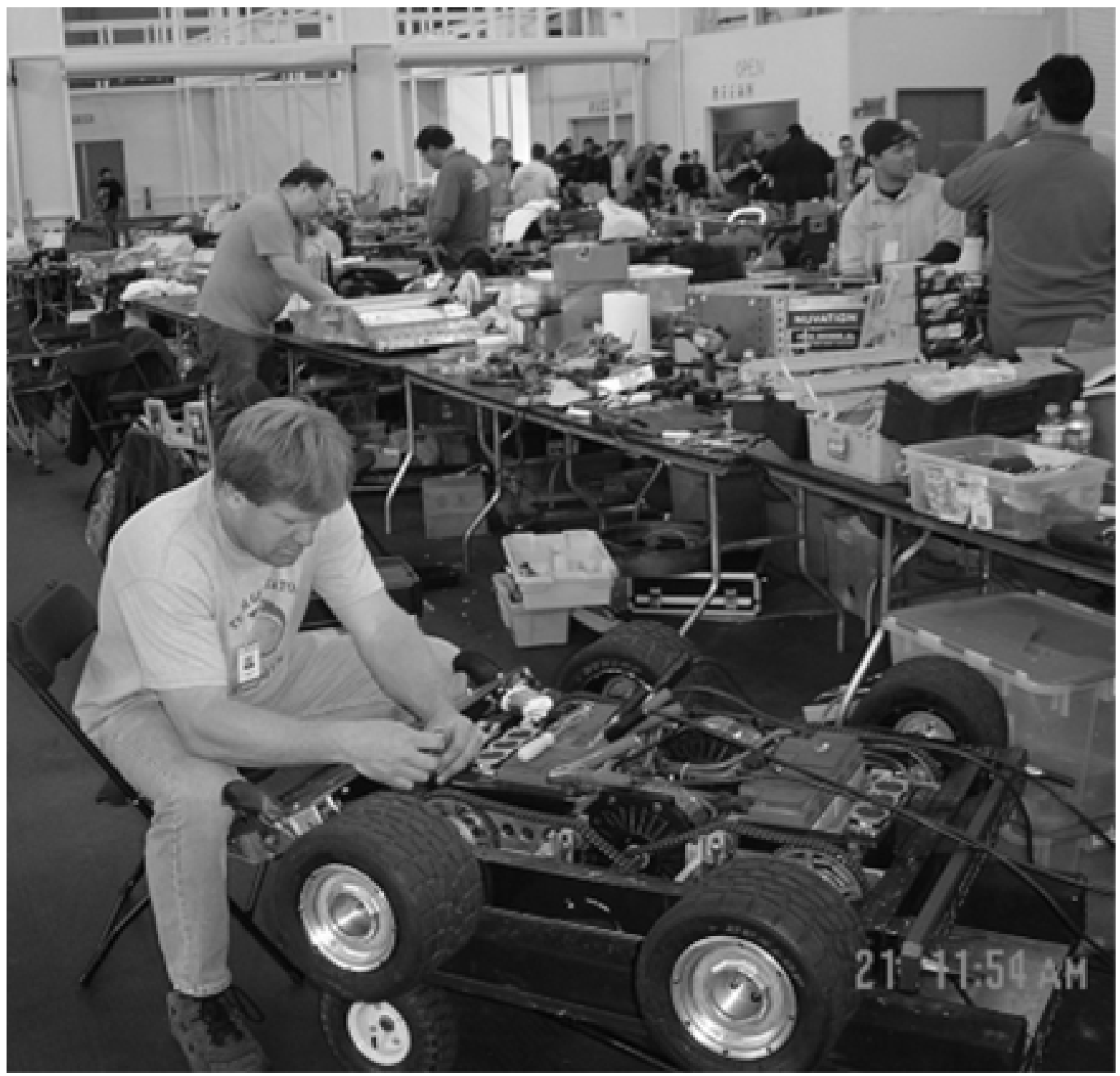

Figure 3: The pits at the 2004 Robolympics in San Francisco California, where the fighting robots are prepared for battle. Photo taken by the author

suggesting that all it allows for is the consumer to make a limited number of choices regarding the adoption of which technology she might prefer. She may only chose those items that are commercially available for instance, and as has been skilfully argued before, these items come preloaded with political, social, aesthetic, and epistemological baggage that the consumer has little control over (Winner 1988, Borgmann 1993, Ihde 1993, Feenberg 1999, Pitt 2000). Feenberg however, argues that the preconfigured rational design goals of those who produce technologies can be altered and an alternative rationality can be reascribed to the technology by its users (Feenberg 1995).
I would argue that in the work of artist like SRL, or in the weekend warrior activities of robot fighting leagues, we see a subversion of commercial and corporate constraints on technology. The robot fighting case study provides another example that gives strength to Feenberg's claim that it is possible for the users of technology to creatively redirect the preconfigured rationality of a particular technology into objects that more suit their user's goals and values. In this instance, it is the goals and values of the skilled hacker that are being expressed in robot fighting. The hacker "ethic" of appropriation and coopting of technology is alive and well in the world of robot fighting. Most of the robots are made from parts found in trash yards or that were originally built 
for some other purpose. A motor designed to raise and lower a window in your car may be used to power a lifting arm on your battle robot, a saw built for construction purposes is now used to lay waste to one's enemies.

This behaviour is similar to that in the hot-rod and low-rider world, where factory built cars of little imagination are wondrously transformed into personal artistic expressions. It is difficult to see anything distasteful about this practice and indeed it is a very hopeful sign, it shows that human creativity can survive and thrive even in the face of powerful technological incentives to conform.

\section{Civil Mirror of Military Might}

The last value I would like to address here is our desire to reflect the military might of the culture to which we belong. With the advent of mechanized warfare in the last century, the machine has become a potent symbol of violence. Of course technology has played an important roll in human warfare from its very beginnings. What is different today is the autonomous nature of the military technology we have now. Where a sword, for instance, has the ability to extend one's bodily capabilities in the commission of violence, it still remains an intimate technology that takes years to master and requires the complete coordination of it's wielders body with the technology. The weapons of today are different; the wielders body is actually more of a hindrance then a facilitator to the technology. Now with the recent developments in tellerobotics warfare, we are able to remove the human body completely from the battlefield. Robot fighting is a way that civilians can partake of this experience and celebrate the warrior culture they belong to. For a generation comfortable with technology and raised with heroic visions of battling anime robots, it is natural for some of us to want to commune with this technology in some way. Fighting robots allows for this by giving their creators the ability to participate in a safe mechanized war. Mark Pauline is right, terrible as it is, war in which you cannot get hurt is fun, or perhaps as Chris Hedges argues in his book of the same name, "war is a force that gives us meaning" (Hedges 2002). Dreadful as it is, we love it, especially when we are winning, and especially when our technology so vastly outstrips those of our enemy as it has in our most recent adventures in the Middle East. As uncomfortable as this revelation is, we need to face it honestly. Perhaps things like Robot Fighting are a, more or less, healthy way for humans to express their violent tendencies since it is only our robotic bodies that are wounded and robots are more easily replaced.
Military Robotics promises to be a growing industry, and many of the emerging robotics companies are moving into this market. It is much more politically expedient to risk a telerobotic weapons platform than a human life. The United States Government realises this, and the LA times reported recently that eighteen robotic soldiers called, SWORDS (Special Weapons Observation Reconnaissance Detection Systems), are headed to Iraq. ${ }^{12}$ These will be the first tellerobotics platforms mounted with guns intended for direct ground combat missions. The battle-bots have left the arena.

\section{Robots in Education}

Amateur robotics in America is not all about robot fighting. In fact there is a much larger segment that uses robotics as an educational tool or just finds entertainment in learning about robotics. In his book Mindstorms, Seymour Papert argues that we need to make our children computer literate, and to achieve this we need to make appropriate computational learning toy/tools for them to use (Pappert 1980). While this need for computer literacy can be argued, Papert's argument has been acted on, resulting in a growing number of robotic learning toys. A number of learning organizations, educational robot competition leagues, and special interest groups have formed around these technologies. I will mention only a few of the most notable among them and briefly describe what they do.

\section{First Robotics Competition}

One of the most well funded, and well known, of these leuges is the First Robotics Competition. This event is the brainchild of the inventor Dean Kamen, and it is intended to, "....create a world where science and technology are celebrated... where young people dream of becoming science and technology heroes...."13 The First organization has leagues for all ages from nine to eighteen, and gives away over $\$ 4.5$ in scholarships to its participants. Each team is paired up with professional engineers who mentor their local team, which tries to earn a birth in the finals that are held every year. At these finals, hundreds of teams compete over a weekend. The older students build very sophisticated machines that are operated telleroboticaly to complete some task like, getting a number of large balls into a hopper, or hanging from a bar twelve feet in the air. The First league has had a number of success stories.

Kamen is found of telling the story of a team made up of remedial students who were able to win the finals in their event. These students were literally in

\footnotetext{
$12 \mathrm{http}$ ://www.mobilerobotics.org/robots/index.php?option=com_content\&task=view\&id=125\&Itemid=2

${ }^{13}$ Quote taken from First Robotics information flyer.
} 
a street gang a short time before and now found themselves in the presence of NASA engineers and loving the experience. They were exposed to an entire new world they did not know existed and received scholarships to attend universities that were well beyond their reach financially.

\section{Botball}

Somewhat smaller but no less interesting is the KISS Institute's Botball Educational Robotics Program. ${ }^{14}$ Partnered with the NASA Robotics Education Program, this group sponsors a tournament every year where teams build small autonomous robots based on the $\mathrm{LEGO}^{\circledR}$ technology. These robots must contend to complete ingenious mazes and technical challenges. This program is geared for middle and high school students and is notable in that the students must learn a lot about robotics programming since the robots are not controlled remotely and must be fully capable of operating on their own. This is a national organization and is a well-run professional group.

\section{Sonoma Robotics}

As an example of the kinds of robotics learning available for grade and middle school children I will give the one I am most familiar with, though there are scores of other programs just like it around the country. ${ }^{15}$ The Sonoma County LEGO ${ }^{\circledR}$ Robot Challenge is in its third year of operation and the number of grade and middle schools that are participating is growing rapidly. The Bay Area Technology Roundtable and other industry groups support this group and they seek to give the students positive experiences dealing with technology, as well as giving them the opportunity to work with mentors from the community that help with the projects and serve as roll models for the students. The LEGO ${ }^{\circledR}$ robotics technologies are so well designed that these young students are able to build and program robots that complete in some fairly demanding tasks.

\section{Learning in the Robotics Society of America}

Learning and exploration in the American amateur robotics movement is not limited to the schoolroom. As an example of non-academic robotic learning there is the Robotics Society of America. ${ }^{16}$ This group holds regular meetings and the chapter in San Francisco California is particularly active in pursuing some of the same kinds of research projects one would find at a university. Many of the members of this group are also involved in robot fighting and this fact along with the competitive nature of all of the other educational robotics groups shows that it is not always easy to completely distinguish between fighting robotics and education. In fact, Battlebots ${ }^{\circledR}$ has a small educational branch of its organization called BattlebotsIQ ${ }^{\circledR}$ that is much like the FIRST league mentioned above.

\section{The social Role of Learning Robotics}

Dean Kamen told a story when he promoted his FIRST robot league during the 2005 RoboNexus conference in San Jose California, where he recounted a discussion he had with the Israeli foreign minister Shamon Perez. Perez is reported to have told Kamen that he wanted him to start a FIRST league in Israel, where Israeli and Palestinian students could compete together, as it was his hope that through learning the shared truths of technology this might allow them to break the bonds of history that kept these two groups at each other's throats. For Perez, science and technology represent truths that transcend culture and these are more important then learning a cultural history that just leads to more bloodshed. Indeed a FIRST league was started there and students from both cultures do compete peacefully with, and against, each other.

It is hard not to be moved by Kamen's stories but we also have to remember that technology is not without its own set of politics and in this way not too different from history. It is right to seek to extend some of the values of our technological society to those that are traditionally left behind, but we also must work to allow these new members to the technological community to show us new ways of looking at what we are doing and learn to take those observations seriously.

\section{The Future of American Amateur Robotics}

The future of American amateur robotics looks very good. The industry of personal robotics is growing rapidly and that will only provide more raw materials for those skilled hackers that live for this technology to alter and mutate in fascinating ways. Since American robotics is largely driven by military research, or the hopes of receiving a military contract, this movement is likely to always be steeped in the violence of robot fighting. But, out of that milieu springs the more important growth of educational robotics, and as long as there is cross-pollination of ideas from other countries, this should remain more of a positive technology then a negative one.

\footnotetext{
${ }^{14} \mathrm{http} / / / \mathrm{www} \cdot$ botball.org/index.html

${ }^{15} \mathrm{http}: / /$ robotics.megagiant.com/sonoma.html

${ }^{16} \mathrm{http}: / /$ www.robots.org/
} 
At the 2004 Robolympics in San Francisco, USA, a very large contingent of amateur roboticists from Asia attended. With them they brought their alternative forms of robot fighting, Robo Sumo, and an event called "Robo One" in which very skilfully crafted miniature humanoid robots competed in dance and movement challenges. These activities did not go unnoticed by the American community and already Americans are building robots to compete in these events. This influence is likely to increase and it is certain that Asia is going to continue to play a very large roll in robotics at all levels and the amateur roboticists of all cultures will continue to trade ideas.

\section{Conclusions}

As we have seen, the costs and logistics of building, programming and maintaining a robotics platform in past generations were too high for the hobbyist or independent researcher, but over the last decade this has radically changed. Amateur robotics clubs are thriving and the knowledge generated by robotics and $\mathrm{AI}$ research of the past is now converging with the home and amateur robotics movement through inexpensive robotics platforms such as the Lego ${ }^{\circledR}$ Mindstorms $\square$ kits. In addition to this, robot-fighting leagues have also become very popular with participants building ingenious machines of destruction that they operate via telerobotics in mock gladiatorial combat. The convergence of high-tech expertise with the home and amateur user represents an example of the successful introduction of AI technology into society and a reciprocal revaluation of that technology by the users themselves.

We have also been able to trace the social values that are driving both the robot fighting leagues, and the educational robotics movements, in America. This growing technology tells us a lot about our relation to technology and the hopes, fears, and dreams we have invested in it. At least some of us have not been content to accept robotics as it was envisioned by past generations, today's amateur roboticists are pushing this technology in new and unforeseen directions, creatively subverting the designs of these technologies towards more democratic uses.

\section{References}

Balthaus, ed. Survival Research Laboratories: S.R.L. Berlin: Vogelsang 1988.

Bing, Alison, and Conley. Robot Riots: The Good Guide to Bad Bots. New York: Barnes and Noble Books, 2001.

Brand, Stewart. Media Lab: Inventing the Future at MIT. New York: Penguin Group, 1987.

Brooks, Rodney A. Flesh and Machines. New York: Pantheon Books, 2002.

Clark, Andy. Natural-Born Cyborgs: Minds, Technologies, and the Future of Human Intelligence. Oxford: Oxford University Press, 2003.

Feenberg, Andrew. Alternative Modernity. Berkeley and Los Angeles: University of California Press, 1995.

-----Questioning Technology. London: Routledge, 1999.

Ferrari, Mario and Giulio. BuildingRobots With Lego ${ }^{\circledR}$ Mindstorms $^{\mathrm{TM}}$. Rockland, MA: Syngress, 2002.

Hedges, Chris. War Is a Force That Gives Us Meaning. Public Affairs, 2002.

Ihde, Don. Philosophy of Technology, Paragon, 1993.

------Bodies in Technology. Minneapolis: University of Minnesota Press, 2002.

Kahney, Leander. Robot Vacs are in the House. Wired,

(http://www.wired.com/news/technology/0,1282,59237,00.html). June 16, 2003

Menzel, Peter, and D'Aluisio. Robosapiens: Evolution of a New Species. Cambridge, MA: MIT, 2000.

McComb, Gordon. The Robot Builder's Bonanza. New York: McGraw-Hill, 2001.

Papert, Seymour. Mindstorms: Children, Computers, and Powerful Ideas. New York: Basic Books, 1980.

Pitt, Joseph C. Thinking About Technology: Foundations of the Philosophy of Technology. New York: Seven Bridges, 2000.

Sullins, John. Transcending the Meat: Immersive Technologies and Computer mediated bodies, in The Journal of Experimental and Theoretical Artificial Intelligence, 2001

Winner, Langdon. The Whale and the Reactor: A Search for Limits in an Age of High Technology. Chicago: University of Chicago Press, 1988. 